\title{
Putting Population-Based Care Into Practice: Real Option or Rhetoric?
}

\author{
Stephen Taplin, MD, Mary Sue Galvin, FNP, Tom Payne, MD, David Coole, MS, \\ and Ed Wagner, MD
}

Background: Efforts to improve care have focused on population-based approaches, though little practical information exists about implementation.

Methods: This report reviews relevant literature on teamwork in the context of a time-series evaluation of a demonstration project to reorganize care of a single panel of patients in a managed care setting. The proportion of the study panel achieving recommended levels for breast and colon cancer screening, warfarin control, and diabetic eye care was compared with the surrounding practice panels and the managed care population as a whole. Using unconditional logistic regression, we compared changes within populations between March 1993 and March 1995, and the rate of change between populations during the same period.

Results: A model of team care was successfully implemented. Colon (occult blood in the stool) and breast (mammography) screening increased more rapidly in the study population than in the surrounding practices or plan as a whole $(P<0.05$ for all comparisons). There was no significant improvement in warfarin control or diabetic eye examinations, though absolute increases occurred.

Conclusion: This work shows that a team approach to population-based care is a real option. Such an approach, however, will not generalize to other settings or all conditions, and its implementation involves some major challenges. (J Am Board Fam Pract 1998;11:116-26.)

Despite the affluence and abundance of health care providers in the United States, our health care system fails to achieve satisfactory levels of basic preventive care and chronic disease management. ${ }^{1,2}$ One vision of how to improve care uses public health and epidemiologic principles to describe a population, analyze care for problems of highest priority, design and modify services to deliver that care, and monitor the results. ${ }^{3-6}$ This approach has been described for geographically defined communities (community-oriented primary care) and populations with specific chronic conditions, ages, or residences. ${ }^{2-4,7-10}$ Most recently there has been an emphasis on the assessment of an individual physician's practice. ${ }^{4,11-13}$ The rhetoric about the importance of this population-based approach far exceeds the demonstration of its success. ${ }^{14}$

The report presented here discusses the feasi-

Submitted, 10 July 1997

From the Center for Health Studies, Group Health Cooperative of Puget Sound, Seattle. Address reprint requests to Stephen Taplin, MD, MPH, Group Health Cooperative of Puget Sound, 1730 Minor Ave, Suite 1600, Seattle, WA 98101-1448.

This research was supported by the Sandy MacColl Institute and the Group Health Cooperative medical staff, who provided assistance with the evaluation and funding for the family nurse practitioner. bility and practical implementation of populationbased care within a physician's practice based on results of a demonstration project and published literature. In the demonstration project we wanted to examine whether we could improve populationbased measures of selected prevention strategies, including (1) screening for occult blood in the stool, (2) breast cancer screening, (3) warfarin control, and (4) diabetic care. In the literature review we briefly highlight how data system development, economic incentives, and a resurgent interest in teams can influence the implementation of population-based care.

The demands of cost control and outcome monitoring have begun to encourage data system development in a way that also supports population-based care. ${ }^{15}$ Constraints on hospital stays and the total growth in health care expenditures have placed a greater emphasis on prevention and early detection as well as outpatient management of disease. ${ }^{16}$ To meet this new demand, providers have begun to consider how they might systematically improve their care for such conditions as hypertension, diabetes, asthma, and cardiovascular disease. ${ }^{2-18}$ People paying for care are now also asking to see measurable results. ${ }^{15}$ The need to improve care and monitor outcomes has pro- 
vided an incentive to build clinical data systems that assist in managing populations. Features of such systems include automated problem lists, medication lists, laboratory results, and rules that apply logical analysis of populations to generate reports and health care reminders. ${ }^{19-22}$

Population-based care, however, is driven by concepts and practices that are not necessarily routine. Implementing population-based care involves planning and initiating care for groups rather than simply responding to the symptoms of individual patients. We started the demonstration project in the belief that achieving population-based care would occur only if we overcame the inertia of individual-oriented practice by completely redesigning how we worked together. ${ }^{19-21}$ This reorganization began with creating a high-performance team. ${ }^{22}$ Once the practice reorganization had begun, we implemented a new clinical system to facilitate practice.

We evaluated the demonstration project to find out whether process measures of care in four areas (breast cancer screening, colon cancer screening, warfarin control, diabetic care) changed significantly compared with those of our colleagues. Although the results of the evaluation cannot be generalized without implementation and evaluation in a larger set of practices, we provide them here as background for a discussion of the challenge and the potential of population-based approaches.

\section{Methods}

This report reviews relevant literature on teamwork in the context of a time-series evaluation of a demonstration project to reorganize care of a single patient panel in a six-panel group within a large staff-model managed care setting. We searched the medical literature using the key words "patient care team," "primary care," "primary health care," "teamwork," "community-oriented primary care," and "population-based," with an emphasis on trials and reviews. We found 22 articles that emphasized general practice from among abstracts of more than 100 publications. We also selected references from the business literature. The sections that follow describe the demonstration project we conducted and its evaluation. Briefly, we established a team structure and then evaluated its impact on care in four specific areas. We measured the proportion of the study panel achieving guideline lev- els for breast and colon cancer screening, warfarin control, and diabetic eye care and compared these findings with those of the surrounding practice panels and the managed care population as a whole. Using unconditional logistic regression, we compared changes within populations between March 1993 and March 1995 and the rate of change between populations during the same time period.

\section{Demonstration Project}

This project took place at Group Health Cooperative of Puget Sound (GHC), a consumer-governed health maintenance organization (HMO) with 398,000 enrollees that delivers most care through a staff model structure. The HMO comprises two hospitals and 27 primary care facilities distributed within several administrative regions in western Washington state. GHC enrollees are of similar age, sex, and racial composition to the surrounding community populations, but they are somewhat better educated and more likely to be in households with middle incomes than the comparably aged general population of Washington state. ${ }^{23}$ All enrollees have a primary care physician, and each primary care physician has a panel of enrollees for which he or she provides most routine care and diagnostic evaluations.

The study practice was within a primary care facility with 6 full-time equivalent (FTE) family physicians who together cared for 9754 enrollees. The 6 family physicians met regularly for discussions of management and clinical issues, but each worked in a separate practice that included a receptionist, a registered nurse, and licensed practical nurse. Our demonstration project occurred between January 1993 and March 1995 using one panel of 1460 enrollees cared for before then by 1 receptionist, 2 half-time physicians, 2 half-time registered nurses, and 1 licensed practical nurse.

\section{Clinical Computing System}

One author (TP) worked with a group of programmers to develop a system that could summarize care for the entire study panel. ${ }^{24}$ Its capabilities included a panel view, which determined adherence to the guidelines we established for all eligible patients in the practice. ${ }^{24}$ We based the guidelines on existing recommendations or the provider team's judgment of current evidence from the medical literature. The provider team prepared 
guidelines for several areas of care but agreed to focus energies upon breast cancer screening, colon cancer screening, warfarin control, and diabetic care during the first 2 years. This process of establishing our own guidelines became a critical part of our team development, because it provided a specific clinical purpose for our work.

Compliance with the guidelines could be determined for an individual patient as well as the entire panel. The computer system was designed to store and display laboratory results, maintain a problem list, specify currently prescribed medications, evaluate compliance with our guidelines, and provide prompts for care on an encounter form generated at the time of a clinical encounter. ${ }^{24}$ For example, at any given time we could tell whether a specific 51-year-old woman had had a mammogram in the previous 2 years. We could also tell the proportion of all women aged 50 years and older with mammograms within that period. By saving compliance data each month, we could graph our progress toward achieving our clinical goals for the entire population.

The rest of the providers at GHC did not have a similar computer system, though they could get individual laboratory and pharmacy data from computerized files. Panel-level data and guideline compliance information were not available to nonstudy GHC physicians except for mammographic screening. 25

\section{Provider Team}

In the project practice group were 2 physicians who shared the practice $(0.9 \mathrm{FTE}$, a receptionist (0.25 FTE), 2 registered nurses who shared 1 position (1.0 FTE), a licensed practical nurse $(0.88$ FTE), and a family nurse practitioner. The family nurse practitioner, also one of the authors (MSG, 0.5 FTE), was hired specifically for the project to provide clinical care (0.25 FTE) and work with another author (ST) to lead the team and its care ( 0.25 FTE). Attending the group meetings were the clinic manager, a clinic pharmacist, and a trained facilitator (a registered nurse with a master's degree in public health and training in the application of total quality management tools ${ }^{26}$ ).

\section{Establishing a Team}

The first organizing steps were to clarify leadership, begin regular meetings, and start forming a team. The group members had been together in meetings and had many years of clinical experience, but they had not functioned as a team. To do so, we needed to establish a common vision and to learn to solve problems by communicating in ways that took advantage of our respective skills. This effort required leadership and encouragement. ${ }^{26,27}$ We had to decide who was to assume responsibility for organizing meetings, setting long-term strategy, and maintaining a vision, ${ }^{26}$ and we needed someone to keep the team focused on its mission and goals in the face of the inevitable resistance to change. ${ }^{19,28}$ The group selected one member to be responsible for overall leadership but also began a process of recognizing greater individual leadership in specific areas. As the team evolved, each member assumed primary responsibility for an area of strength or interest, including each of the four clinical areas and the data system.

With leadership clarified, the next steps in team development included (1) writing the ground rules for meetings, (2) composing a mission statement, (3) defining short-term goals to address the mission, (4) clarifying the individual participant's roles, and (5) prioritizing the team's activities. These steps, well recognized in medical literature of the early 1970 s and rediscovered in the business literature of the 1990s, 27,29-31 seemed so obvious that the group did not want to slow down to do them. A concerted effort was required to complete the steps in the face of the demands of hospitalized patients, acute-care telephone calls, and the immediate needs of the sickest patient. Through this process the group established a common purpose, a safe working environment for honest communication, and groundwork for future decision making.

\section{Improving Clinical Care}

With the groundwork complete, the group could focus on processes of care. Business literature recognizes that teams are a means, not an end.22 Our group became a high-performance team when the processes for problem solving were in place and achieving clinical goals became its clear purpose. The team established the following set of criteria for selecting clinical problems: (1) the problem or condition has high priority for clinical improvement at GHC and is widespread in our practice, (2) evidence exists for an optimal medical outcome or treatment plan, (3) effective tools are available to improve the process of care, (4) the problem and solution interest the team, (5) a gap exists between 
Table 1. Sample Agenda for Team Meetings.

\begin{tabular}{lr}
\hline Meeting Characteristics & Time Allocated \\
\hline Review/modify agenda & $5 \mathrm{~min}$ \\
Clinical updates & $25 \mathrm{~min}$ \\
Guideline 1 & $30 \mathrm{~min}$ \\
$\quad$ Review content & \\
$\quad$ Review implementation steps & $10 \mathrm{~min}$ \\
Guideline 2 & \\
$\quad$ Review status of education materials & $15 \mathrm{~min}$ \\
Issues/updates & $5 \mathrm{~min}$ \\
Meeting evaluation & $1-1.5 \mathrm{hr}$ \\
Total time & \\
\hline
\end{tabular}

current and optimal health care practices, and (6) the effort enhances the team focus on prevention.

At the beginning of the project, we gathered demographic information about our practice and the most common diagnoses. We also discussed the general characteristics of our work environment, including how it facilitated and obstructed the achievement of our mission. We then researched the available literature and used clinical information and knowledge of our own practice to apply the above-described criteria to the most frequent diagnoses in our population. Finally, within clinical areas of high priority, we detailed our goals, analyzed our process of care, clarified roles within the team, and implemented process changes that we hoped would improve the chances of achieving our goals. We regularly reviewed graphic presentations of the panel view for guideline compliance in high-priority clinical areas. This graphic feedback provided the information and inspiration to continue working on our care.

\section{Team Meetings}

During the first year of the project we scheduled hour-long weekly meetings; by the second year, however, we were able to meet every 2 weeks for 1.5-hour sessions. The meetings overlapped with lunch and afternoon patient care time. Each team meeting, which was planned in advance, required a 1-hour meeting of the team leaders, plus additional family nurse practitioner time to prepare materials and meet with other team members. The team leaders drafted and posted an agenda before each meeting (Table 1), distributed materials relevant for discussion, and clarified what decisions needed to be addressed during the meeting.

During the team meeting we discussed the changes we were making in the process of providing care and our work toward achieving compliance with the recommended guidelines. We were also able to review difficult management cases in our inpatient and outpatient practice and address administrative issues. The administrative issues threatened to take over the meeting during the early stages, so we moved them to the end of the agenda. This change did not appear to influence our day-to-day administration, but it did allow time to emphasize clinical care during the meeting.

\section{Team Member Roles}

The roles of the team members evolved with time. During the several meetings we spent having each member describe his or her role, we became aware of the need for communication to reduce duplication of effort. During the course of the project, roles shifted away from a preoccupation with acute care toward a greater emphasis on chronic care.

\section{Demonstration Project Evaluation}

We measured descriptive characteristics and compliance with guidelines in three populations: the demonstration project panel, the surrounding practices, and GHC as a whole. Descriptive characteristics included age, sex, length of enrollment, and chronic disease score. The latter used 1 year of pharmacy data to calculate a score that correlates highly with subsequent hospitalization and a physician's perception of the person's health. ${ }^{32}$

Using data available for all the practices, we measured guideline compliance in the three populations by estimating the proportion of each population that met one or more of the following criteria (these patients were continuously enrolled for the entire period relevant to the criterion):(1) men and women aged 52 years and older who had stool sampled for occult blood within the previous 18 months, (2) women aged 52 to 65 years who had a mammogram in the previous 2 years, (3) men or women on warfarin therapy (defined from GHC pharmacy records by taking warfarin twice in the last 7 months or once in the last 2 months) who had a prothrombin time measured within the previous month, and (4) men and women with diabetes who had an eye care visit within the previous year. Having diabetes was defined by meeting one or more of the following criteria: (1) taking any of two therapeutic classes of drugs for diabetes in the last 3 years, (2) having a total glycosylated hemo- 
Table 2. Panel Characteristics (Baseline) Compared With Other Populations.

\begin{tabular}{lccc}
\hline Characteristic & Study Panel & $\begin{array}{c}\text { Surrounding } \\
\text { Practices }\end{array}$ & $\begin{array}{c}\text { Group Health } \\
\text { Cooperative }\end{array}$ \\
\hline Age, yr & & & $36.09^{\dagger}$ \\
$\quad$ Mean & 47.67 & $35.07^{\star}$ & 37 \\
$\quad$ Median & 46 & 35 & $208,858(53)$ \\
Sex, n & & & $183,770(47)$ \\
$\quad$ Female (\%) & $685(47)$ & $4657(56)$ & \\
$\quad$ Male (\%) & $775(53)$ & $3637(44)$ & $8.9^{\dagger}$ \\
Enrollment, yr & & & 7.0 \\
$\quad$ Mean & 14.8 & $9.6^{*}$ & 392,628 \\
$\quad$ Median & 14.9 & 8.4 & $1.04^{\dagger}$ \\
Enrollees, $\mathbf{n}$ & 1460 & 8294 & $0.87^{\star}$ \\
Chronic disease score, ${ }^{\ddagger}$ mean & 1.35 & & \\
\hline
\end{tabular}

*Surrounding practices vs study panel $P \leq 0.0001$.

${ }^{\dagger}$ Group Health Cooperative vs study panel $P \leq 0.0001$.

${ }^{\ddagger}$ Based on score for 1992 , approximately $97 \%$ of patients.

globin measurement of $7.5 \mathrm{~g} / \mathrm{dL}$ or greater in the previous year, (3) having a fasting plasma glucose level of $140 \mathrm{mg} / \mathrm{dL}$ or greater in the previous year, (4) having a random plasma glucose level of 200 $\mathrm{mg} / \mathrm{dL}$ or greater in the previous year, or (5) hospital discharge diagnosis of diabetes at any time during their history with GHC.

We evaluated population-based process of care measures at four points during the demonstration project: March 1993-immediately before implementation of the clinical system, March 1994, September 1994, and March 1995. For comparison we obtained measures in the surrounding five practices and in GHC as a whole exclusive of the study and surrounding five practices.

\section{Analysis}

Based on March 1993 data, we compared mean age, years of enrollment, and chronic disease score using a two-sample t-test. To compare compliance with each criterion (colorectal screening and breast cancer, warfarin monitoring, and diabetes care) we evaluated the measures according to whether there was a difference in the proportion meeting each criterion with time, and whether the rate of change in meeting each criterion was faster in the study population than in other populations.

To evaluate change in guideline implementation for each population meeting the criterion for care with time (March 1993 to March 1995), we used unconditional logistic regression with guideline compliance (yes or no) as the dependent variable and time points as the covariates. To compare the rate of change in the study practice, surrounding practices, and GHC population, we combined the data for these three populations, added a covariate for population, and tested whether a timeby-population interaction term contributed significantly to the model. If it did, then the proportion meeting the criteria differed across time for that population when compared with the others.

\section{Results}

Table 2 displays the differences between the study population, the surrounding practices, and GHC as a whole. That the study group included enrollees who were generally older and facing a higher burden of disease than patients in other practices is reflected in the higher age and mean chronic disease score. When we examined the top 10 diagnoses in our practice, we found hypertension, diabetes, and angina pectoris occurred more frequently in our practice than in the others, which was consistent with the greater disease burden in our practice. Nevertheless, routine health maintenance remained the primary reason for visits in our practice and throughout GHC.

Based on the distribution of these diagnoses and the criteria described above, the demonstration practice focused its activities on the cancer-screening portion of routine health maintenance and diabetic care. Because monitoring warfarin therapy resulted in a high level of anxiety for the team, care processes relevant to starting and tracking patients on warfarin were also addressed.

The enrollees in the demonstration practice 


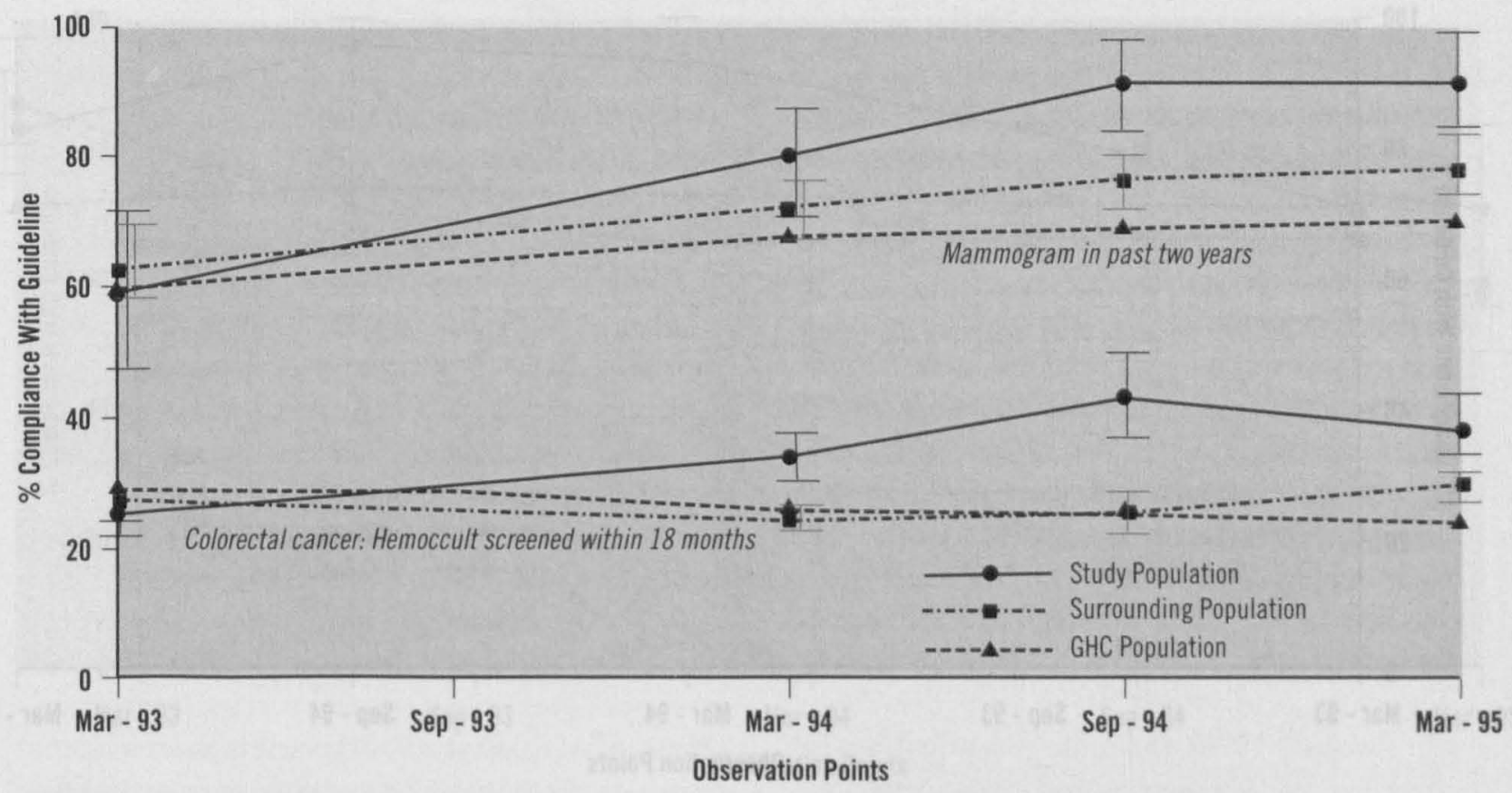

Figure 1. Cancer screening compliance: study population versus surrounding practices versus Group Health Cooperative (GHC) population as a whole.

had a longer mean enrollment in GHC. By the end of the study, 83 percent of the study population remained enrolled in GHC compared with 79 percent in the surrounding practices and 79 percent in GHC in general. Within the original study population, 69 percent remained in the practice throughout the observation period compared with 71 percent who remained in the surrounding practices. Of note is that a physician who had been with the practice for 20 years left during the study and was replaced by a temporary physician for 4 months before a permanent replacement joined the practice.

Figure 1 shows the proportion of the study population aged 52 through 65 years who had a mammogram within the previous 2 years among an eligible study population that ranged from 77 to 92 women. All three populations showed significant increases in their rates with time $(P<0.001)$. The rate of rise in the study population was faster than in either the surrounding practices $(P<0.01)$ or GHC populations $(P<0.001)$.

Figure 1 also shows the increase in stool occult blood screening within the study population, which ranged from 565 to 466 eligible patients. Between the baseline and the final measurement, occult blood screening increased significantly in the study group $(P<0.001)$ but not in the surrounding practices $(P=0.207)$. The rate actually decreased in $\mathrm{GHC}$ as a whole $(P<0.001)$. The rate of rise was significantly faster for the study group compared with the surrounding practices $(P$ $<0.017)$. By the end of the observation period, the proportion of study group patients who had screening tests for occult blood within the previous 18 months was significantly higher than proportion in either the surrounding practice populations or GHC as a whole.

Figure 2 shows there was no change from baseline in the rate of warfarin testing compliance at the end of the study in either the study group or in GHC as a whole, though the practices surrounding the study group did have an improved rate $(P<0.04)$. The number of eligible study patients on warfarin therapy increased from 15 to 22 during this period.

Figure 3 shows that eye care compliance was high in the study population $(\mathrm{n}=59)$ at baseline and improved with time, but not significantly, probably because of insufficient power to detect the difference. Eye care compliance did improve in the surrounding practices $(P=0.034)$ and in GHC as a whole $(P<0.0001)$, but this improvement was in part due to their low initial levels of compliance.

\section{Discussion}

This work shows potential for the challenge of putting population-based care into practice. Such 


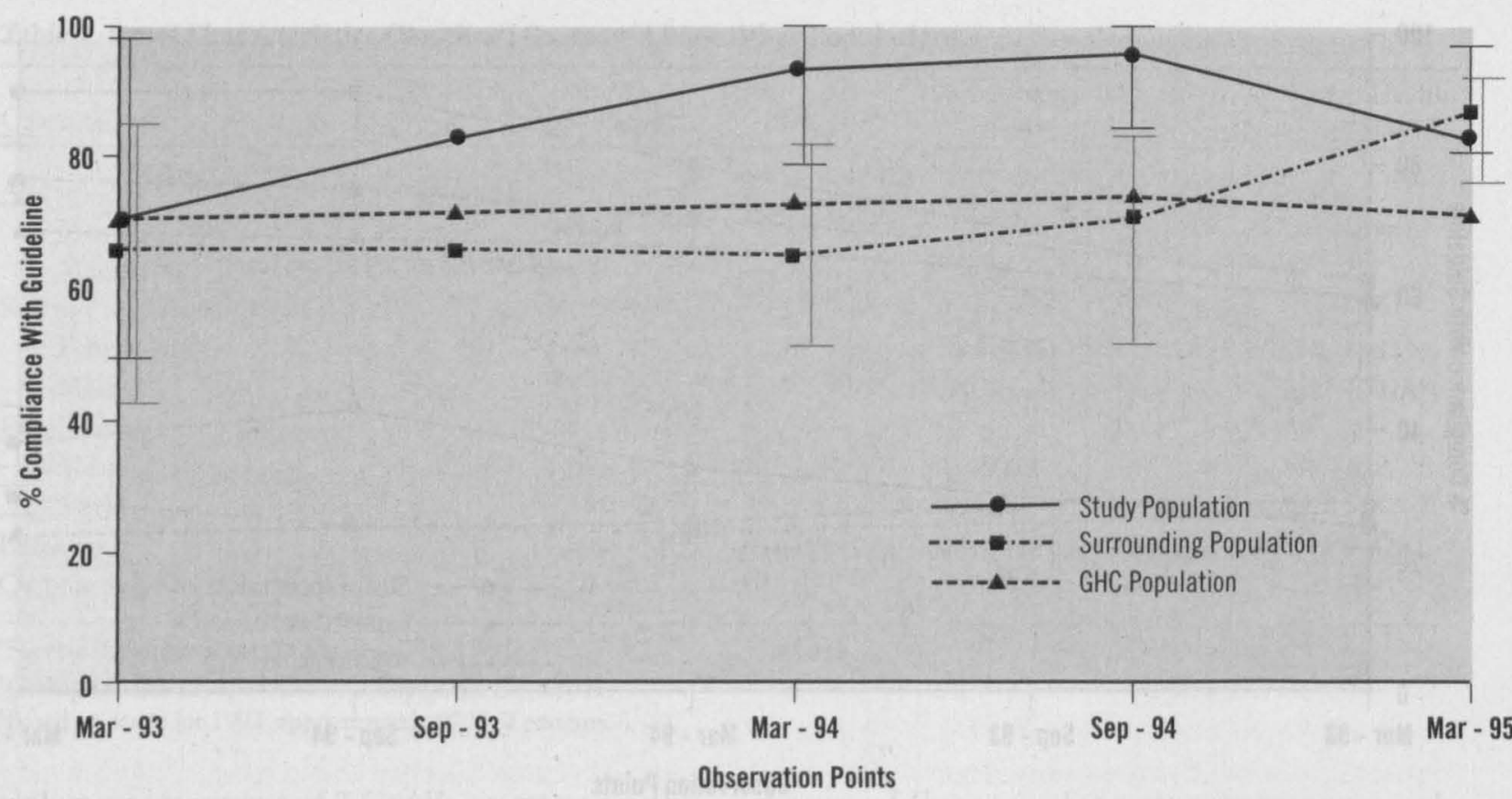

Figure 2. Warfarin monitoring in the study population, surrounding practices, and Group Health Cooperative population as a whole.

an approach can be more than rhetoric, but we cannot conclude yet that it is viable in general. Carney and others ${ }^{28,33}$ showed that study practices could improve the delivery of cancer screening, but it was unclear whether practices without the external support of a grant-funded program could achieve the same level of success. In this effort we found that with limited external support we could establish a team which used information systems to achieve some success in improving our process of care.

Though we showed some success, our results also reflect the challenges of sustaining changes. Colorectal cancer screening rates dropped somewhat from their peak in September 1994, as did warfarin therapy compliance. The change in colorectal cancer screening rates, although small, points out the need to remain persistently attentive. Populations change, and patients can become noncompliant as time passes, so the team must continually examine how well it is achieving its goals. The panel view summary provides critical information, but the team also needs to use this information to initiate care and achieve its goals. Clearly such an approach is a change from the traditional practice of responding to individual symptoms and patient's requests. The drop in warfarin compliance reflects the issue of sustaining change, but the fluctuations were also due to the low number of eligible patients in the study practice. One or two more patients out of compliance had a much larger impact on the proportion compared with surrounding practices.

Because these results are derived from a single practice, whether other practices would achieve similar success remains unclear. The only comparable evidence is the patterns of care in our surrounding group. In the spring of 1994 other practices began implementing our warfarinmonitoring plan and population-based approaches to diabetic care. The study practice did not show a significant improvement in diabetic eye care even though our absolute compliance increased. We had only a few diabetic patients, so showing a significant improvement was more difficult in our group than in the pooled population of the surrounding practices.

Whether the improvements in the surrounding practices reflected general improvements in care or dissemination effects from our practice cannot be established. It is interesting to note, however, that improvements for $\mathrm{GHC}$ as a whole did not mirror those in other surrounding practices, which suggests some influence upon our peers. Whether changes will disseminate to all practices within this HMO or are applicable in other settings remains to be seen.

Certain characteristics of the study might limit 


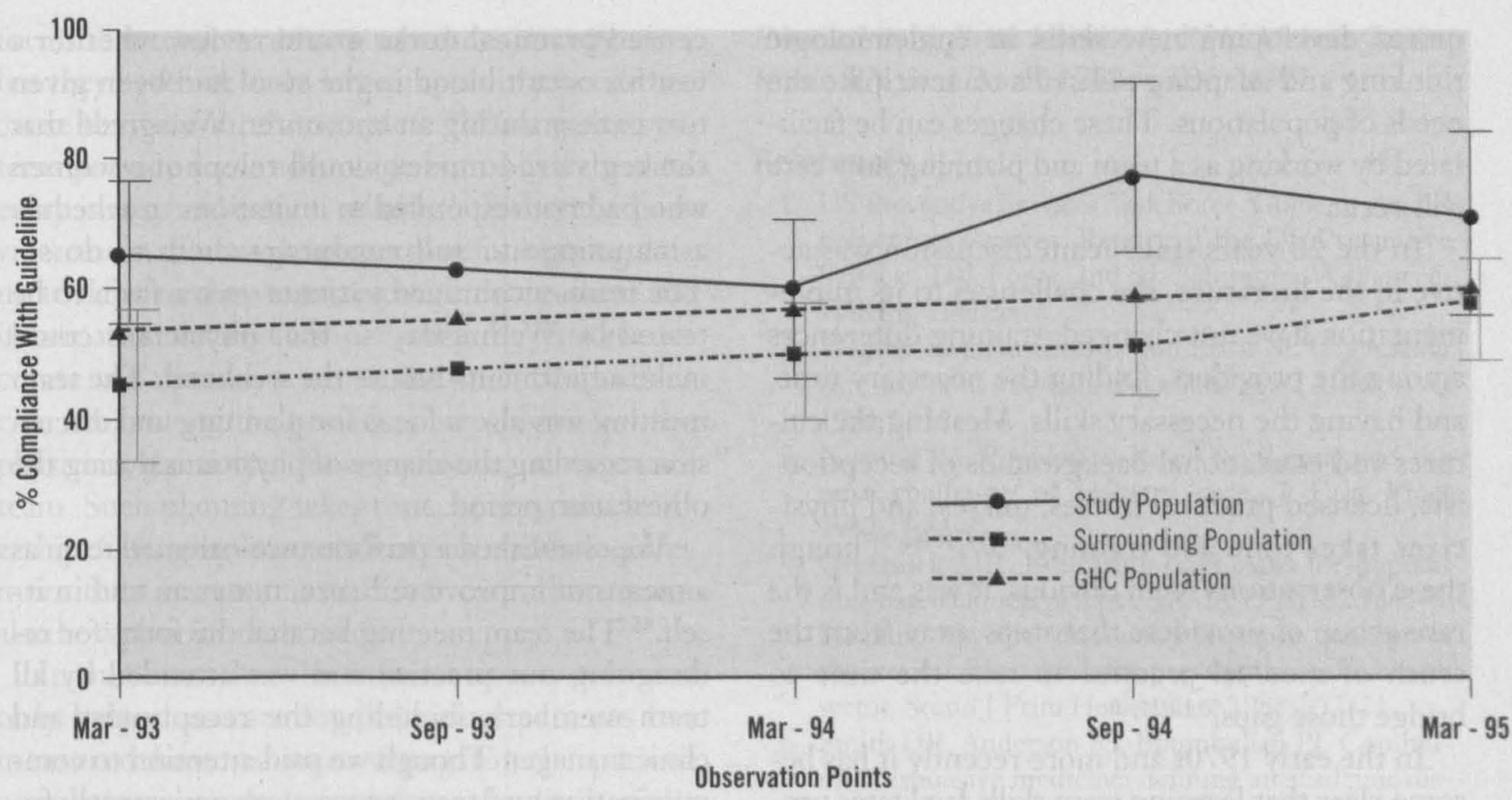

Figure 3. Diabetic eye care in the study population, surrounding practices, and Group Health Cooperative (GHC) population as a whole.

generalizability even as they contributed to its success. We cannot separate the effect of having the reminder and measurement tools from the effect of reorganizing the team. Carney et $\mathrm{al}^{28}$ refer to the teamwork necessary to implement their tools. In our effort we consciously chose to develop our team for patient care in general and had a facilitator help us with that process. It is unclear whether another team given the same tools would achieve similar success without concentrating on its team development. Our group was also highly motivated to prove that we could create a difference in practice by the end of the period, when the tools and nurse practitioner might disappear. We used that motivation to concentrate our activities on very specific measurable processes. Whether the high level of motivation would occur in other practices without something to prove is also unclear, but the recent push by purchasers of care to have measurable evidence of care quality might motivate others.

The high level of motivation and effort to incorporate multiple changes might have made the practice exceptional, but they might also have provided a lesson regarding changes in primary care. Though we cannot say from this evaluation that it took motivation and the development of three related aspects of primary care to achieve our success, it is at least intriguing to consider this possi- bility. All three aspects have been discussed recently in the medical literature: team development, ${ }^{34,35}$ information systems for clinical practice, ${ }^{36,37}$ and population-based care. ${ }^{3,4,9}$ Each are discussed in greater detail below, but motivation to perform was a driving force, and team development, information systems, and population-based care were the tools to get there.

Team development has shown a recent rebirth in the medical literature after an active period 20 years ago. ${ }^{16,27,30,34,38-43}$ This rebirth coincides with the economic pressures to become more productive, control medical care costs, and improve prevention. ${ }^{15,19,44}$ Primary medical care providers appear to be a logical group of people to form a team. The receptionist, business manager, nurse, medical assistant, and physician each contribute valuable skills that could benefit from cooperative rather than parallel effort. Achieving more than the sum of the individual group members efforts is a key characteristic of teamwork. ${ }^{45}$

Faced with the need to provide technically competent acute, chronic, and preventive care while maintaining economic viability would seem to be the perfect motivation to pull group members together. In a practice each team member contributes different skills to care. Traditionally these skills are focused on responding to the demands of acute care. Population-based care re- 
quires developing new skills in epidemiologic thinking and adapting old skills to anticipate the needs of populations. 'These changes can be facilitated by working as a team and planning how care will occur.

In the 20 years since team discussion was active in the literature, the challenges to its implementation have not changed: training differences among the providers, finding the necessary time, and having the necessary skills. Meshing the cultures and educational backgrounds of receptionists, licensed practical nurses, nurses, and physicians takes time and training. ${ }^{30,34,40,42}$ Though these observations seem obvious, it was and is the rare group of providers that steps away from the crush of medical practice to take the time to bridge those gaps. ${ }^{2,19,21,40}$

In the early 1970 s and more recently it has become clear that learning team skills facilitates progression through predictable steps in developing a functional team. ${ }^{27,34,46}$ The steps include forming the team, experiencing a period of conflict among members with different personalities and backgrounds (storming), accommodating the differences and establishing team norms (norming), and finally performing. ${ }^{34,47}$ Team skills include providing leadership, sharing leadership, taking time to establish a mission, setting up normative expectations, emphasizing the positive contributions of each member, and listening well. ${ }^{34}$

During the course of the project we used a seven-point scale to assess team functioning and to show improvement in all measures. For example, our team's self-assessment of the openness of communication, recognition and utilization of member resources, and effectiveness of problem solving procedures went from a mean of $4.5,3.2$, and 3.8, respectively, to 5.6, 5.5, and 6.2. Comparable measures are not available from other teams, and our members were certainly capable of biased reports, but the numbers provide some reassurance that the practice was improving its process.

Our team development effort took the time to bridge the gaps among team members, but perhaps more importantly we focused those efforts within the context of improving our clinical care. In so doing, we streamlined communication among team members, clarified roles, and devised strategies to increase our compliance with our automated guidelines. For example, we addressed the concrete task of clarifying that the li- censed practical nurse would review whether a test for occult blood in the stool had been given to a patient during an encounter. We agreed that the registered nurses would telephone women who had not responded to invitations to schedule a mammogram and encourage them to do so. The team encouraged patients on warfarin to be tested by Wednesday so that physicians could make adjustments before the weekend. The team meeting was also a focus for planning and discussion regarding the change of physicians during the observation period.

We established a performance-oriented team as a means to improve our care, not as an end in itself. ${ }^{45}$ The team meeting became the focus for redesigning our practice and was attended by all team members, including the receptionist and clinic manager. Though we paid attention to communication and team process, we persistently focused and refocused our discussion on the common conditions in our practice, such as the welladult visit, diabetes care, and cancer screening. This focusing and refocusing upon clinical care necessarily led to reviews of team member roles, responsibilities, and practice styles. We defined our criteria for good care, developed measures of how we were meeting those criteria, and then improved our processes.

What distinguishes team efforts today from what occurred 20 years ago is that we have information systems and the motivation to use them. Though computer tools were recognized for their potential in the 1970s, they have only recently begun to be implemented into care. ${ }^{37,41}$ The computer became a clarifying resource. We had a timeline to implement the computer system and a need to be clear about how we would use it. Once in place, the computer system could prompt us regarding the care of an individual patient as well as summarize how we were doing for the entire panel. In the 1970 s teams were motivated to deal with perceived manpower shortages. ${ }^{40,41}$ Today we are trying to improve care within a competitive marketplace that includes purchasers of care asking for quality assurance. The information system provides information for the purchasers and a tool for the providers.

It is unclear, however, whether the information system was a necessary component of our effort. Even if information systems are not automated, there are means of implementing reminders. Paper 
forms that track screening schedules are effective, but they have not had a large impact in practice because they are rarely complete. ${ }^{48}$ Computer systems provide some advantage but only if the data entry is easy and occurs reliably. ${ }^{37}$ Either the provider and staff must develop a plan for keeping data up to date, or they need a system that gathers the information automatically. Even if the data are accurate and reminders occur, the practice must decide who among the providers is responsible-the physician, the nurse, the receptionist, or the entire team. Such planning takes time, energy, and leadership. Changing how medical care occurs requires more than systems to facilitate care; there must also be a plan for their use. ${ }^{49}$

In our case, that the information system not only helped us care for individual patients but measured how we were doing for the patient population as a whole is perhaps the distinguishing feature of our system. Paper systems cannot provide these measures even if they provide prompts for care. Population-based thinking about care, previously the province of researchers, can now help clinicians because we have the tools to make measurements and the tools provide the reinforcement for team development. In day-to-day practice, for instance, providers can tell whether a patient's angina resolves. Without tools to make population-based measures, however, providers have a hard time knowing how they are really doing. In fact, anecdotal information can undermine a team's function because there will be inevitable deaths and complications that occur in individual patients. Without the reinforcement of population-based measures, it is hard for a team to recognize their success. Our team became excited about seeing the progress in our chosen measures of care.

Despite the success, it is clear that the a population-based approach required time and commitment that might not easily translate into practice. Our interest was showing that it was possible. Whether the information systems and incentives for care will support the spread of this approach remains to be seen or perhaps even be tested.

This project would not bave been possible without the support of Pat Stafford, $R N$, and Bill Affolter, $M D$, and the team members at the Group Health University Medical Center: Regina Green, LPN, Dianne Quimby, RN, Mike Stuart, MD, Tom Horst, MD, Tammie
Braunscbweig, Brita Kimmerly, RPh, Melodie Jaques

Kunis, RN, and Dorotby Talbot, RN, MPH.

\section{References}

1. US Preventive Services Task Force. Guide to clinical preventive services. Report of the US Preventive Services Task Force. 2nd ed. Baltimore: Williams \& Wilkins, 1996:xxvi.

2. Wagner EH, Austin BT, Von Korff M. Organizing care for patients with chronic illness. Milbank Q 1996;74:511-44.

3. Nutting PA. Population-based family practice: the next challenge of primary care. J Fam Pract 1987;24:83-8.

4. Greenlick MR. Educating physicians for population-based clinical practice. JAMA 1992;267:1645-8.

5. Haglund BJ. The community diagnosis concept - a theoretical framework for prevention in the health sector. Scand J Prim Health Care 1988;1:11-21.

6. Smith DR, Anderson RJ, Boumbulian PJ. Community responsive medicine: defining an academic discipline. Am J Med Sci 1991;302:313-8.

7. Cowen ME, Bannister $M$, Shellenberger R, Tilden $R$. A guide for planning community-oriented health care: the health sector resource allocation model. Med Care 1996;34:264-79.

8. McCulloch D, Glasgow RE, Hampson SE, Wagner E. A systematic approach to diabetes management in the post-DCCT era. Diabetes Care 1994;17:765-9.

9. Kvale JN, Gillanders WR, Buss TF, Hofstetter CR, Gemmel D. Health and poverty among elderly persons: a community-oriented primary care survey. J Am Board Fam Pract 1990;3:231-9.

10. Schned ES, Doyle MA, Glickstein SL, Schousboe JT, Reinertsen JL, Baglioni AJ, et al. Team managed outpatient care for early onset chronic inflammatory arthritis. J Rheumatol 1995;22:1141-8.

11. Nutting PA, Nagle J, Dudley T. Epidemiology and practice management: an example of communityoriented primary care. Fam Med 1991;23:218-26.

12. Nutting PA, Connor E, Institute of Medicine. Community oriented primary care: a practical assessment I: the Committee report. Washington DC: National Academy Press, 1984.

13. Nutting PA, Connor E, Institute of Medicine. Community oriented primary care: a practical assessment II: the Committee report. Washington DC: $\mathrm{Na}$ tional Academy Press, 1984.

14. O'Connor PJ. Is community-oriented primary care a viable concept in actual practice? An opposing view. J Fam Pract 1989;28:206-8.

15. Shortell SM, Gillies RR, Devers KJ. Reinventing the American hospital. Milbank Q 1995;73:131-60.

16. Smith CS. The impact of an ambulatory firm system on quality and continuity of care. Med Care 1995; 33:221-6.

17. Van Damme R, Drummond N, Beattie J, Douglas G. Integrated care for patients with asthma: views of general practitioners. Br J Gen Pract 1994;44:9-13. 
18. Pearson SD, Goulart-Fisher D, Lee TH. Critical pathways as a strategy for improving care: problems and potential. Ann Intern Med 1995;123:941-8.

19. Thompson RS, Taplin SH, Davis BV, Payne T, Stuart $M$, Wagner $E$. How to organize a large health care system for the development and delivery of preventive care services. In: Woolf SH, Jonas S, Lawrence RS, editors. Health promotion and disease prevention in clinical practice. Baltimore: Williams \& Wilkins, 1996:483-504.

20. Carter WB, Belcher DW, Inui TS. Implementing preventive care in clinical practice: II. Problems for managers, clinicians and patients. Med Care Rev 1981;38:195-216.

21. Woolf SH, Jonas S, Lawrence RS, editors. Health promotion and disease prevention in clinical practice. Baltimore: Williams \& Wilkins, 1996:xxv.

22. Katzenbach JR, Smith DK. The discipline of teams. Harvard Business Review 1993;71:111-20.

23. Campbell KM, Holm K. Preventive service utilization: among older women: a comparison of HMO Members, private insurance policy holders, and Medicare recipients. Olympia Wa: Washington State Department of Health, Center for Health Statistics, 1995.

24. Payne TH, Galvin M, Taplin SH, Austin B, Savarino $J$, Wagner EH. Practicing population-based care in an HMO: evaluation after 18 months. HMO Pract 1995;9:101-6.

25. Thompson RS, Taplin SH, Carter AP, Schnitzer F. Cost effectiveness in program delivery. Cancer 1989;64:2682-9.

26. Scholtes $P$. The team handbook: how to use teams to improve quality. Madison, Wisc: Joiner Associates, 1994.

27. Rubin IM, Beckhard R. Factors influencing the effectiveness of health teams. Milbank Mem Fund $Q$ 1972;50:317-35.

28. Carney PA, Dietrich AJ, Keller A, Landgraf J. Tools, teamwork, and tenacity: an office system for cancer prevention. J Fam Pract 1992;35:388-94.

29. Huszczo GE. Training for team building. Training Develop J 1990;44:37-43.

30. Huffman MC. Family physicians and the health care team. Can Fam Physician 1993;39:2165-70.

31. Beck J, Yeager N. Moving beyond team myths. Training Develop 1996;50:51-5.

32. Von Korff $M$, Wagner EH, Saunders K. A chronic disease score from automated pharmacy data. J Clin Epidemiol 1992;45:197-203.

33. Davis JE, McBride PE, Bobula JA. Improving prevention in primary care: physicians, patients, and process. J Fam Pract 1992;35:385-7.

34. Anderson LK. Teams: group process, success, and barriers. J Nurs Adm 1993;23:15-9.

35. Toseland RW, O'Donnell JC, Engelhradt JB, Hendler SA, Richie JT, Jue D. Outpatient geriatric evaluation and management: results of a randomized trial. Med Care 1996;34:624-40.

36. Frame PS, Zimmer JG, Werth PL, Martens WB. Description of a computerized health maintenance tracking system for primary care practice. Am J Prev Med 1991;7:311-8.

37. Ornstein SM, Garr DR, Jenkins RG, Musham C, Hamadeh G, Lancaster C. Implementation and evaluation of a computer-based preventive services system. Fam Med 1995;27:260-6.

38. Barnard $D$. The viability of the concept of a primary health care team: a view from the medical humanities. Soc Sci Med 1987;25:741-6.

39. Landefeld CS, Aucott J. Improving primary care in academic medical centers: the role of firm systems. Med Care 1995;33:311-4.

40. Kindig DA. Interdisciplinary education for primary health care team delivery. J Med Educ 1975;50:97110.

41. Spitzer WO. Issues for team delivery and interdisciplinary education: a Canadian perspective. J Med Educ 1975;50:117-21.

42. Wise $H$. The primary-care health team. Arch Intern Med 1972;130:438-44.

43. Peterson ML. Educational programs for team delivery. Interdisciplinary education of health associates: the Johns Hopkins experience. J Med Educ 1975;50:111-7.

44. Smith HE, Herbert CP. Preventive practice among primary care physicians in British Columbia: relation to recommendation of the Canadian Task Force on the Periodic Health Examination. Can Med Assoc J 1993;149:1795-800.

45. Katzenbach JR, Smith DK. The wisdom of teams: creating the high-performance organization. New York: Harper Business, 1994.

46. Horak BJ, Guarino JH, Knight CC, Kweder SL. Building a team on a medical floor. Health Care Manage Rev 1991;16:65-71.

47. Tuckman BW, Jensen MA. Stages of small group development revisited. Group Organizational Studies 1977;2:419-27.

48. Frame PS. Computerized health maintenance tracking systems: a clinicians guide to necessary and optional features. A report from the American Cancer Society Advisory Group on Preventive Health Care Reminder Systems. J Am Board Fam Pract 1995; 8:221-9.

49. Mahloch J, Taylor V, Taplin SH, Urban N. A breast cancer screening educational intervention targeting medical office staff. Health Educ Res 1993;8:567-79. 